\title{
RARE EARTH METALS IN ZINC OXIDE RICH BOROPHOSPHATE GLASSES
}

\author{
Georgi PATRONOV, Irena KOSTOVA, Dan TONCHEV \\ University of Plovdiv "Paisii Hilendarski", Department of Chemical Technology, Plovdiv, Bulgaria, EU, \\ patron@uni-plovdiv.bg
}

https://doi.org/10.37904/metal.2019.941

\begin{abstract}
The focus of present research is on the behaviour of rare earth metals as dopants in zinc oxide rich borophosphate glasses. Attention is turned on the influence of $\mathrm{Sm}, \mathrm{Eu}, \mathrm{Gd}$ and $\mathrm{Nd}$ on the structure and optical properties of these new materials. Analysed glasses $71.81 \mathrm{ZnO}-18 \mathrm{~B}_{2} \mathrm{O}_{3}-9.69 \mathrm{P}_{2} \mathrm{O}_{5}-0.5 \mathrm{RE}_{2} \mathrm{O}_{3}(\mathrm{~mol} \%)$ were prepared by conventional melting quenching method. The ratio of the main components $-\mathrm{ZnO}, \mathrm{B}_{2} \mathrm{O}_{3}$, $\mathrm{P}_{2} \mathrm{O}_{5}$; the content of the dopant rare earth element $(\mathrm{Sm}, \mathrm{Eu}, \mathrm{Gd}, \mathrm{Nd})$ and the conditions of synthesis and analysis are set on the basis of literature data and our previous studies. The structure of the synthesized samples was investigated by powder X-ray diffraction, differential scanning calorimetry and infrared spectroscopy, and their optical properties - by photoluminescence analysis.

The synthesized rare earth doped glasses are mainly amorphous with the presence of one or more crystalline phases in some of them $-\mathrm{SmPO}_{4}, \mathrm{GdPO}_{4}$ and $\mathrm{NdPO}_{4}$. They have the typical structure of borophosphate glasses - the presence of $\mathrm{PO}_{4}$ tetrahedra and $\mathrm{BO}_{4}$ tetrahedra. The high glass transition temperature of the synthesized materials (above $500{ }^{\circ} \mathrm{C}$ ) is an indication of the stability of the glasses obtained. The RE-doped $\mathrm{ZnO}$-rich borophosphate glasses have a potential for practical application in optical devices for engineering, electronics and medicine.
\end{abstract}

Keywords: Rare earth metals, doped zinc borophosphate glasses, $x$-ray powder diffraction, differential scanning calorimetry, photoluminescence

\section{INTRODUCTION}

The progress of science, engineering and technology requires the development and introducing of new materials. Rare earth metals with their characteristic optical properties due to $4 f-4 f$ or $4 f-5 d$ electronic transitions are increasingly demanding and attractive in recent decades. When rare earth metals are added to the glass matrix as dopants, it enhances some unique glass properties, such as optical and electrical and associated fluorescent effects [1].

Nowadays, rare earths are becoming a vital wealth of advanced materials and technologies (catalysts, alloys, magnets, optical components and lasers, electronics, economical lighting, conversion of wind and solar energy). It could say that they are like jewels for functional materials of the future $[2,3]$.

Production and demand for rare earth metals has increased more than twice over the last decade. China dominates both globally (over $80 \%$ ) and as supplier to the European Union (over $90 \%$ ). They are included in many modern technological devices - fuel cells, mobile phones, displays, superconductors, electromagnets, catalysts and others. Rare earths ( $\mathrm{La}, \mathrm{Y}, \mathrm{Nd}, \mathrm{Sm}, \mathrm{Gd}, \mathrm{Dy}, \mathrm{Ce}, \mathrm{Pr}, \mathrm{Eu}$ ) are widely used in luminescent materials for example, for lighting (fluorescent lamps), displays (liquid crystal displays, plasma televisions), lasers (DVD players), and medical diagnostic (positron emission tomography). This is because of their intrinsic properties, which derive from their unpaired $4 \mathrm{f}$ electrons [4].

Rare earth doped zinc borophosphate compositions are of particular interest. Attention is to the change of optical, mechanical and thermal properties, depending on the different ratio of $\mathrm{ZnO}, \mathrm{B}_{2} \mathrm{O}_{3}, \mathrm{P}_{2} \mathrm{O}_{5}$ and the content of the rare earth dopants [5]. $\mathrm{ZnO}-\mathrm{B}_{2} \mathrm{O}_{3}-\mathrm{P}_{2} \mathrm{O}_{5}$ ternary system is the most thoroughly investigated from $\mathrm{Ji}$ et al. There are seven binary compounds and one ternary compound $\left(\mathrm{Zn}_{3} \mathrm{BPO}_{7}\right)$ in the system. Ten ternary phase 
regions were determined and no solid-solution composition ranges were found. The small region $\mathrm{ZnO}-$ $\mathrm{Zn}_{3}\left(\mathrm{BO}_{3}\right)_{2}-\mathrm{Zn}_{3}(\mathrm{PO} 4)_{2}$ contains the relatively low-melting compounds $\mathrm{Zn}_{3}\left(\mathrm{BO}_{3}\right)_{2}, \mathrm{Zn}_{3}\left(\mathrm{PO}_{4}\right)_{2}$, and $\mathrm{Zn}_{3} \mathrm{BPO}_{7}[6]$. Glasses synthesized and studied by us have a composition close to this area.

The present investigations are directed to the synthesis and structure characterization of new rare earth doped ZnO-rich borophosphate glasses: $71.81 \mathrm{ZnO}-18 \mathrm{~B}_{2} \mathrm{O}_{3}-9.69 \mathrm{P}_{2} \mathrm{O}_{5}-0.5 \mathrm{RE}_{2} \mathrm{O}_{3}(\mathrm{~mol} \%)$. The ratio of the main components - $\mathrm{ZnO}, \mathrm{B}_{2} \mathrm{O}_{3}, \mathrm{P}_{2} \mathrm{O}_{5}$, the content of the dopant rare earth metal ( $\mathrm{Sm}, \mathrm{Eu}, \mathrm{Gd}, \mathrm{Nd}$ ), and the conditions of synthesis and analysis are set on the basis of literature data and our previous studies $[7,8]$.

The structure of the synthesized compositions was investigated using a combination of techniques such as powder X-ray diffraction, differential scanning calorimetry and infrared spectroscopy, and their optical properties - by photoluminescence analysis.

\section{EXPERIMENTAL}

\subsection{Sample preparation}

All samples were prepared by conventional melt quenching method using $\mathrm{ZnO}, \mathrm{P}_{2} \mathrm{O}_{5}, \mathrm{~B}_{2} \mathrm{O}_{3}$ and $\mathrm{RE}_{2} \mathrm{O}_{3}$ as starting materials $(\mathrm{RE}=\mathrm{Sm}, \mathrm{Eu}, \mathrm{Gd}, \mathrm{Nd}$ ). The reagents were thoroughly mixed, grinded, placed in alumina crucibles and heated at $950{ }^{\circ} \mathrm{C}$ for 3 hours in a muffle furnace. The obtained homogeneous melts were then poured onto a graphite plate. Then the samples were annealed at $250{ }^{\circ} \mathrm{C}$ for 2 hours. Synthesized compositions are amorphous, homogeneous, non-hygroscopic and predominantly transparent glasses. They are easily reproducible.

\subsection{Analytical procedures}

Powder X-ray diffraction analysis

Powder X-ray diffraction data were collected on Bruker D8 Advance powder diffractometer with $\mathrm{Cu}-\mathrm{Ka}$ radiation source $(\lambda=1.5406 \mathrm{~nm})$ and Lynx Eye PSD detector, in steps of 0.020 over the range of $10^{\circ}-80^{\circ} 2 \theta$, with a time per step of $2.8 \mathrm{sec}(32 \mathrm{~kW}, 15 \mathrm{~mA})$. The phases in the XRD patterns were identified using the Diffract Plus EVA v.12 program and ICDD PDF-2 database [9].

Differential Scanning Calorimetric analysis

DSC measurements were performed using TA Instruments DSC Q100 and DSC 2910 with attached Fast Air Cooling System (FACS) and Refrigerating Cooling System (RCS). The samples (20 - $22 \mathrm{mg}$ ) were placed in aluminium hermetic pans. A heating rate of $10 \mathrm{~K} / \mathrm{min}$ was used.

\section{Infrared spectroscopy analysis}

The Infrared spectroscopy studies were conducted using the VERTEX 70 FT-IR (BRUKER OPTICS) Infrared Fourier Transform Spectrometer with $\mathrm{KBr}$ pellets in the region $4000-400 \mathrm{~cm}^{-1}$.

\section{Photoluminescence measurements}

The photoluminescence spectra were recorded using Go Direct SpectroVis Plus spectrophotometer with excitation sources $\lambda=405 \mathrm{~nm}$ in the wavelength range of $380-950 \mathrm{~nm}$.

\section{RESULTS AND DISCUSSION}

List of the synthesized zinc borophosphate glasses is presented in Table 1.

The results obtained from Powder X-ray diffraction analysis show that the samples are amorphous (Figure 1), with the presence of crystalline phases in some of them (Figure 3). The main crystalline phases identified in these samples are indexed as $\mathrm{NdPO}_{4}$ (sample 2 - powder diffraction file PDF 00-025-1065 Monazite-(Nd), syn, 
sample 5 and sample 6 - PDF 01-078-1167 Neodymium Phosphate), GdPO 4 (sample 4 - PDF 00-032-0386 Gadolinium Phosphate) and $\mathrm{SmPO}_{4}$ (sample 4 - PDF 01-083-0655 Monazite-(Sm), syn) from ISDD PDF-2 data-base using DiffractPlus EVA v.12 program. Identified crystalline phases are phosphates of rare earth metals and refer to the neodymium doped samples and that with gadolinium, and samarium. All these phases are characterized by a monoclinic lattice and space group P21/n (14) [9].

Table 1 Composition of rare earth doped zinc borophosphate samples

\begin{tabular}{|c|c|c|c|c|c|c|c|}
\hline \multirow{2}{*}{$\begin{array}{c}\text { Sample } \\
\text { (№) }\end{array}$} & \multicolumn{7}{|c|}{ Composition (mol\%) } \\
\cline { 2 - 8 } & $\mathrm{ZnO}$ & $\mathrm{P}_{2} \mathrm{O}_{5}$ & $\mathrm{~B}_{2} \mathrm{O}_{3}$ & $\mathrm{Sm}_{2} \mathrm{O}_{3}$ & $\mathrm{Eu}_{2} \mathrm{O}_{3}$ & $\mathrm{Nd}_{2} \mathrm{O}_{3}$ & $\mathrm{Gd}_{2} \mathrm{O}_{3}$ \\
\hline 1 & 71.81 & 9.69 & 18.0 & - & 0.5 & - & - \\
\hline 2 & 71.81 & 9.69 & 18.0 & - & - & 0.5 & - \\
\hline 3 & 71.81 & 9.69 & 18.0 & - & - & - & 0.5 \\
\hline 4 & 71.81 & 9.69 & 18.0 & 0.25 & - & - & 0.25 \\
\hline 5 & 71.81 & 9.69 & 18.0 & 0.25 & - & 0.25 & - \\
\hline 6 & 71.81 & 9.69 & 18.0 & - & - & 0.25 & 0.25 \\
\hline
\end{tabular}

The results from Differential Scanning Calorimetry (DSK) are presented in Figure 2. The high glass transition temperature is an indication of the stability of the glasses obtained. Neodymium doping significantly increases the glass transition temperature.

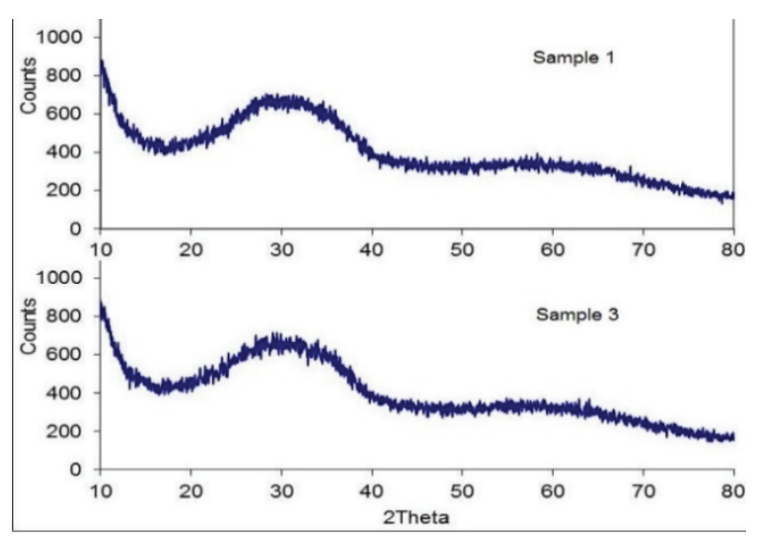

Figure 1 Powder X-ray diffraction patterns for samples

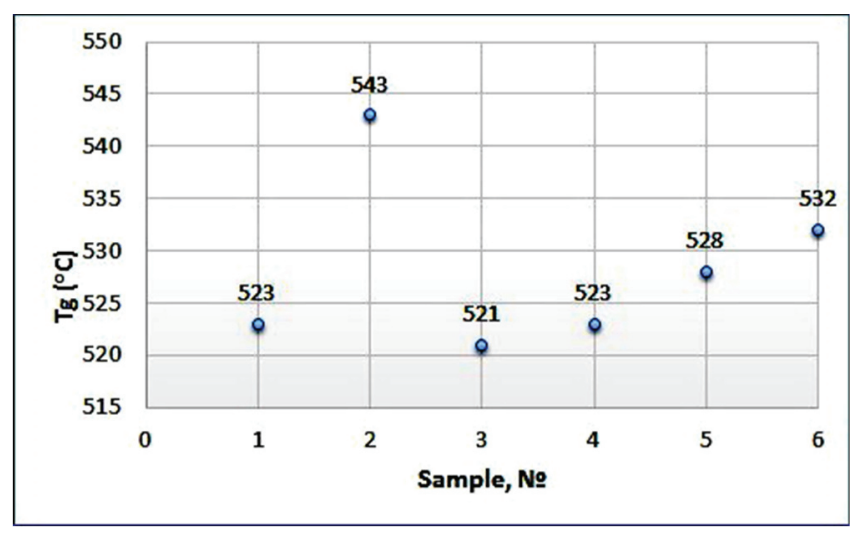

Figure 2 Glass transition temperatures of the samples 1 to 6

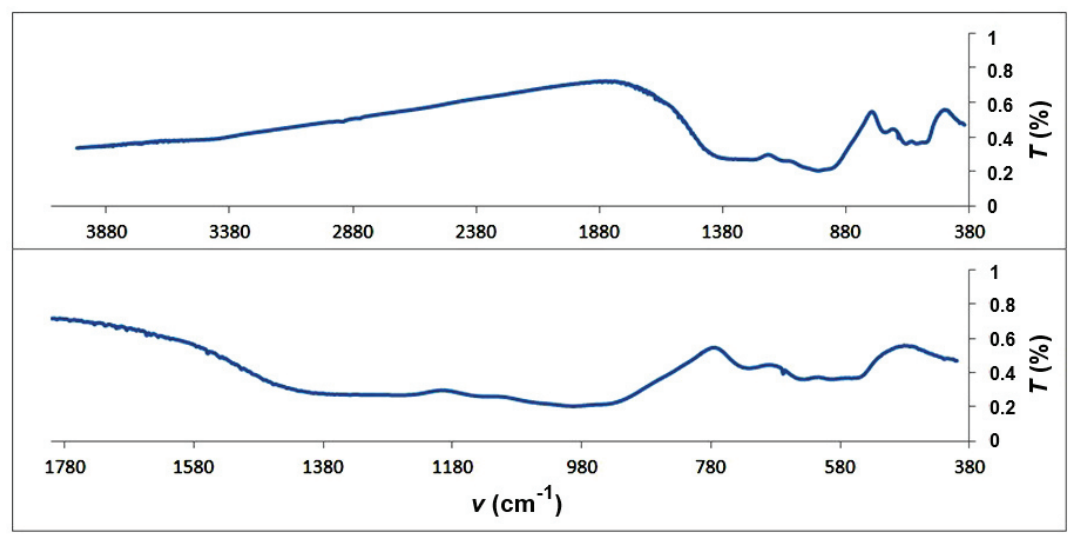

Figure 4 Infrared spectra of the sample 1 

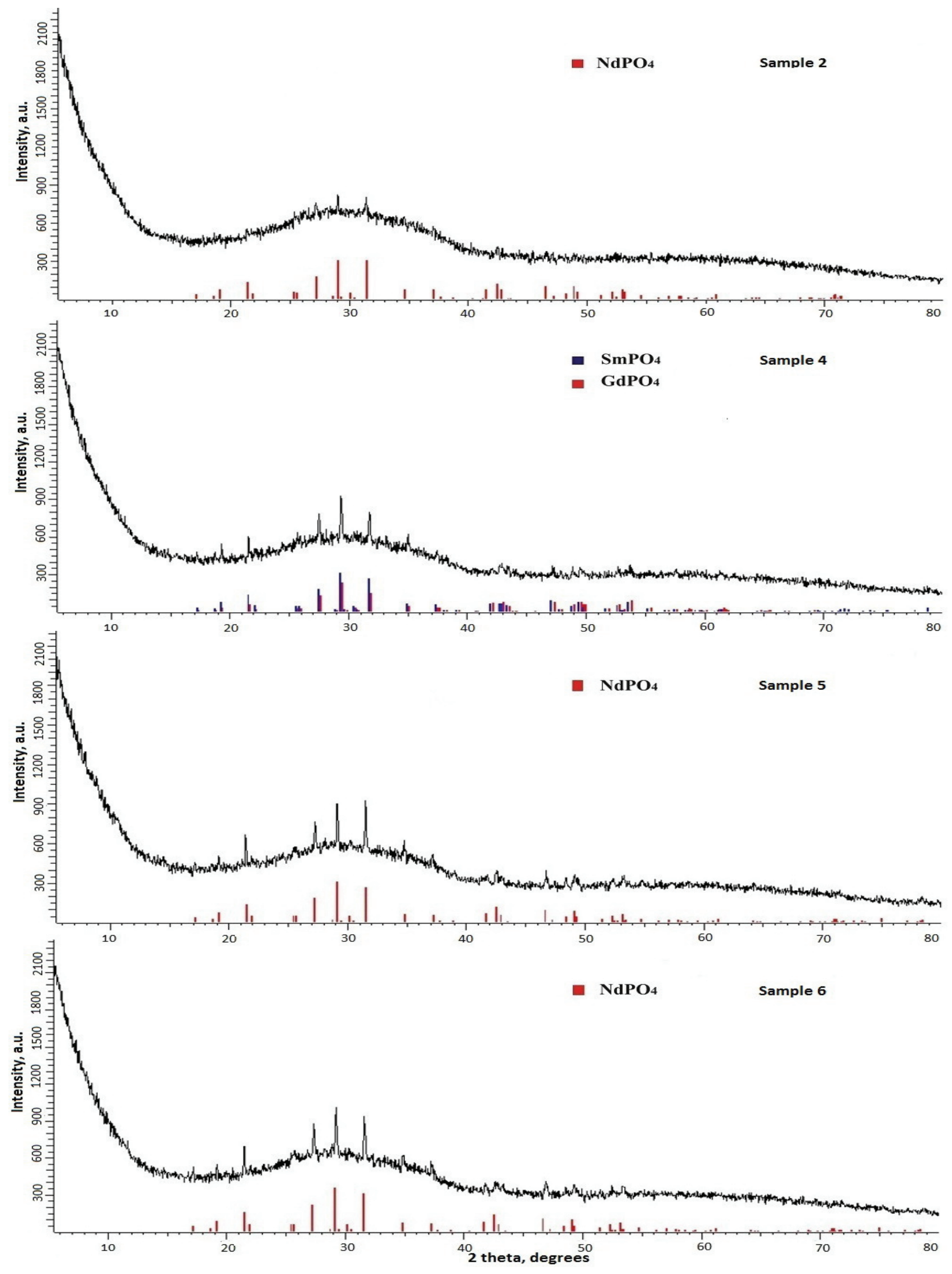

Figure 3 Powder X-ray diffraction patterns for samples 2, 4, 5 and 6 
The Figure 4 represents the infrared spectra of the as-synthesized zinc borophosphate glasses - Eu doped sample №1.

Absorption band about $990 \mathrm{~cm}^{-1}$ is due to the vibration of the structural unit $\mathrm{BO}_{4}$, the peak around $730 \mathrm{~cm}^{-1}$ is determined by the symmetrical vibration P-O-P. Absorption band about $640 \mathrm{~cm}^{-1}$ is determined by the vibration of the structural unit $\mathrm{BO}_{3}$ and peaks about $560 \mathrm{~cm}^{-1}$ - by stretching vibration $\mathrm{P}-\mathrm{O}-$. The results are in agreement with literature data on the structure of borophosphate glasses [10-12].

The most efficient excitation source for the glasses is the one at $405 \mathrm{~nm}$ according to our previous research [13]. Representative emission spectra for synthesized samples are illustrated in Figure 5.

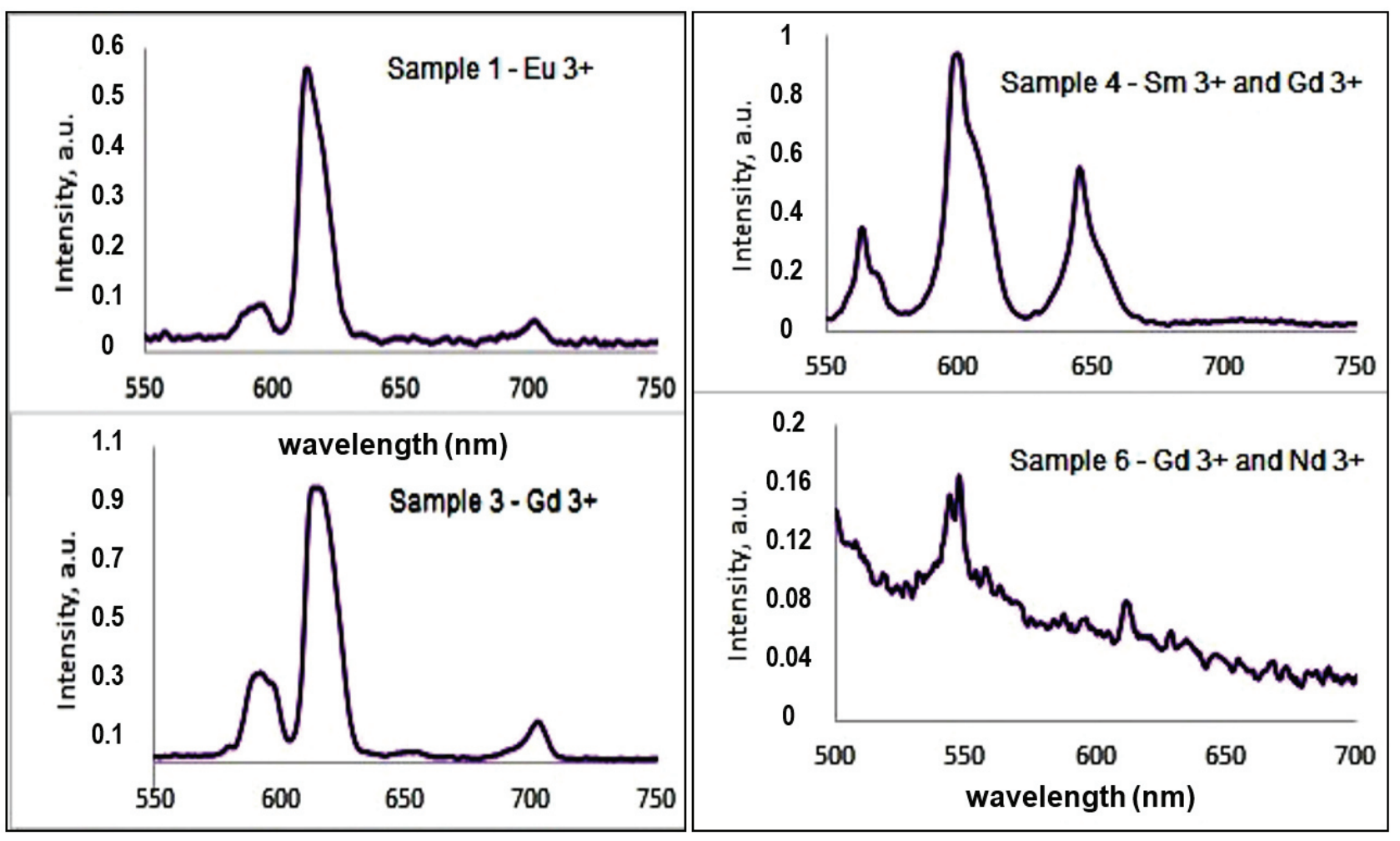

Figure 5 Photoluminescence spectra for rare earth doped samples

All rare earth doped samples are optically active with a photoluminescence signal out of $\mathrm{Re}^{3+}$ ions [13]. The source used is not suitable for samples containing neodymium. Therefore, rare earth ions effectively activate the oxide matrix. This evidences the opportunity to use the rare earth doped zinc borophosphate glasses for application in optical devices.

The rare earth doping and co-doping of materials play an important role in the structural, thermal and optical properties of glasses, as evidenced from the presented results.

\section{CONCLUSIONS}

Zinc oxide rich borophosphate glasses doped with rare earth metals ( $\mathrm{Sm}, \mathrm{Eu}, \mathrm{Gd}, \mathrm{Nd}$ ) have been synthesized and investigated by powder X-ray diffraction, IR spectral analysis, differential scanning calorimetry and photoluminescence spectroscopy.

The obtained materials are homogeneous, non-hygroscopic and transparent glasses. The high glass transition temperature is an indication of the stability of the glasses obtained. They are amorphous, with the presence of crystalline phases in some of them. The synthesized compositions have the typical structure of borophosphate 
glasses - the presence of $\mathrm{PO}_{4}$ tetrahedra and $\mathrm{BO}_{4}$ tetrahedra. The main crystalline phases observed are Neodymium Phosphate $\mathrm{NdPO}_{4}$, Gadolinium Phosphate $\mathrm{GdPO}_{4}$ and Samarium Phosphate $\mathrm{SmPO}_{4}$.

The content of rare earth metals and doping of materials play an important role in the structural and optical properties of compositions.

Rare earth doped samples exhibit strong fluorescence for different doping ions.

The synthesized RE doped ZnO-rich borophosphate glasses have a potential for practical application in optical devices.

\title{
ACKNOWLEDGEMENTS
}

\begin{abstract}
We are grateful to the National Program of the Ministry of Education and Science "Young Scientist and Postdoctoral Students", Bulgaria, Assist. Prof. Dr. Tzvetkov of the Institute of General and Inorganic Chemistry (Bulgarian Academy of Science) for his help with powder X-ray diffraction measurements, Assist. Prof. Dr. Tsoneva of Plovdiv University for its help with the Infrared spectra analysis.
\end{abstract}

\section{REFERENCES}

[1] RAMTEKE, D., BALAKRISHNA, A., KUMAR, Vijay and SWART, H., Luminescence dynamics and investigation of Judd-Ofelt intensity parameters of $\mathrm{Sm}^{3+}$ ion containing glasses. Optical materials. 2017. vol. 64, pp. 171-178.

[2] ELISEEVA, Svetlana V. and BÜNZLI, Jean-Claude G., Rare earths: jewels for functional materials of the future. New Journal of Chemistry. 2011. vol. 35, no. 6, pp. 1165-1176.

[3] REDDY, C. M., RAJU, B. D. P., SUSHMA, N. J., DHOBLE, N. S. and DHOBLE, S. J. A review on optical and photoluminescence studies of $\mathrm{RE}^{3+}(\mathrm{RE}=\mathrm{Sm}, \mathrm{Dy}, \mathrm{Eu}, \mathrm{Tb}$ and $\mathrm{Nd})$ ions doped LCZSFB glasses. Renewable and Sustainable Energy Reviews. 2015. vol. 51, pp. 566-584.

[4] SIKANDER, A., SAVVILOTIDOU, V., JIA, X. and NICIMEL, N. The presence of rare earth elements and critical metals in waste electric and electronic equipment: challenges for recovery. Global NEST Journal. 2018. vol. 20, no. 4, pp. 773-777.

[5] KOUDELKA, L. and MOSNER, P., Borophosphate glasses of the $\mathrm{ZnO}-\mathrm{B}_{2} \mathrm{O}_{3}-\mathrm{P}_{2} \mathrm{O}_{5}$ system. Materials Letters, 2000, vol. 42, no. 3, pp. 194-199.

[6] JI, L. N., LI, J. B., LIANG, J. K., SUN, B. J., LIU, Y. H., ZHANG, J. Y. and RAO, G. H. Phase relations and flux research for $\mathrm{ZnO}$ crystal growth in the $\mathrm{ZnO}-\mathrm{B}_{2} \mathrm{O}_{3}-\mathrm{P}_{2} \mathrm{O}_{5}$ system. Journal of Alloys and Compounds. 2008. vol. 459, no. 1-2, pp. 481-486.

[7] SESHADRI, M., RADHA, M., RAJESH, D., BARBOSA, L. C., CORDEIRO, C. M. B. and RATNAKARAM, Y. C. Effect of $\mathrm{ZnO}$ on spectroscopic properties of $\mathrm{Sm}^{3+}$ doped zinc phosphate glasses. Physica B: Condensed Matter. 2015. vol. 459, pp. 79-87.

[8] PATRONOV, G., KOSTOVA, I. and TONCHEV, D. Synthesis and characterization of samarium doped zinc borophosphate glasses. Bulgarian Chemical Communications. 2017. vol. 49, Special Issue A, pp. 40-45.

[9] DiffractPlus EVA v.12 program and ICDD (The International Centre for Diffraction Data) PDF-2 database (2009).

[10] CHEN, P., LI, S., QIAO, W. and LI, Y. Structure and crystallization of $\mathrm{ZnO}-\mathrm{B}_{2} \mathrm{O}_{3}-\mathrm{P}_{2} \mathrm{O}_{5}$ glasses. Glass Physics and Chemistry. 2011. vol. 37, no.1, pp. 29-33.

[11] KIM, Young-Seok, CHOI, Won-Gyu and RYU, Bong-Ki. Effect of ZnO content change on the structure and properties of zinc borophosphate glasses. Glass Physics and Chemistry, 2014. vol. 40, no. 4, pp. 408-414.

[12] DEEPA, A. V., MURUGASEN, P., MURALIMANOHAR, P., SATHYAMOORTHY, K. and VINOTHKUMAR, P. A comparison on the structural and optical properties of different rare earth doped phosphate glasses. Optik. 2019. vol. 181, pp. 361-367.

[13] KOSTOVA, Irena; PATRONOV, Georgi and TONCHEV, Dan. Luminescent properties of rare earth doped ZnO$\mathrm{B}_{2} \mathrm{O}_{3}-\mathrm{P}_{2} \mathrm{O}_{5}$ glasses. Journal of Chemical Technology and Metallurgy. 2018. vol. 53, n0. 6, pp. 1087-1094. 